\title{
Reliability of Resources in the Digital-Based Learning
}

\author{
Maen Odeh \\ Higher Colleges of Technology, Al Ain - United Arab Emirates
}

\begin{abstract}
Immersed in the avalanche of digital information on the various platforms of resources, students as well as ordinary people are often puzzled how (or do not pay enough attention) to distinguish accurate information and/or reliable resources. In this paper, factors affecting college students' attitude to test reliability of resources and accuracy of information are explored. The paper also presents the findings of a case study on developing the thinking skill of testing reliability of resources by infusing teaching the skill in the curriculum and developing a thinking map to help students develop the skill and transfer it to real life contexts.
\end{abstract}

Keywords: digital information; reliability of resources; infusing teaching; thinking skill; digitalbased learning 